\title{
$100 \%$ Electrification in automotive India... feasible? : An insight into the challenges headed up towards future
}

\author{
N.L.Balasudarsun ${ }^{1}$, R.Chitra ${ }^{2}$, R.Jagajeevan ${ }^{3}$ \\ \{balajeemba@gmail.com ${ }^{1}$, chitra@psgim.ac.in ${ }^{2}$, jagan@psgim.ac.in $\left.{ }^{3}\right\}$ \\ PSG college of Technology, Coimbatore, India.
}

\begin{abstract}
E-mobility has been a buzz word since few years and 100\% across the entire auto industry is thrilling the automakers and consumers because of the unveiling uncertainties day by day. Dreams when realized face difficulties and this dream is sure to shake the entire Indian economy because of its footprints in the entire economic model. The below case throws light on the ill- effects of air pollution and how e-mobility can honestly fit into the shoes of an efficient emission reducer. The case also brings up the challenges that the Government is embedded upon and tries to assess the consumer behavior from different perspectives to accept this transition. The phase out of a technology that powered the vehicles for several decades is not easy and replacing the conventional internal combustion engines with battery powered alternative requires complete restructuring of the automotive framework within Indiaand is a great challenge moving forward.
\end{abstract}

Keywords: . E-mobility, auto industry, Indian economy, emission reducer.

\section{IntroductionAir pollution}

Air is an important entity without which survival is impossible. The quality of our health depends largely also on the quality of air we breathe. The said air quality is completely dependent on how well we preserve it with care.

Among the various forms of pollution, air pollution draws significant attention because of the impact it has on the lives. Though invisible, it occupies a place in the top 5 factors leading to mortality across the globe.

India with its ample population and automotive growth is highly prone to air pollution and also strike a massive mortality number when assessed globally. Vehicle emissions is one of the key components of fine air pollution, and it has grown exponentially over the years. 


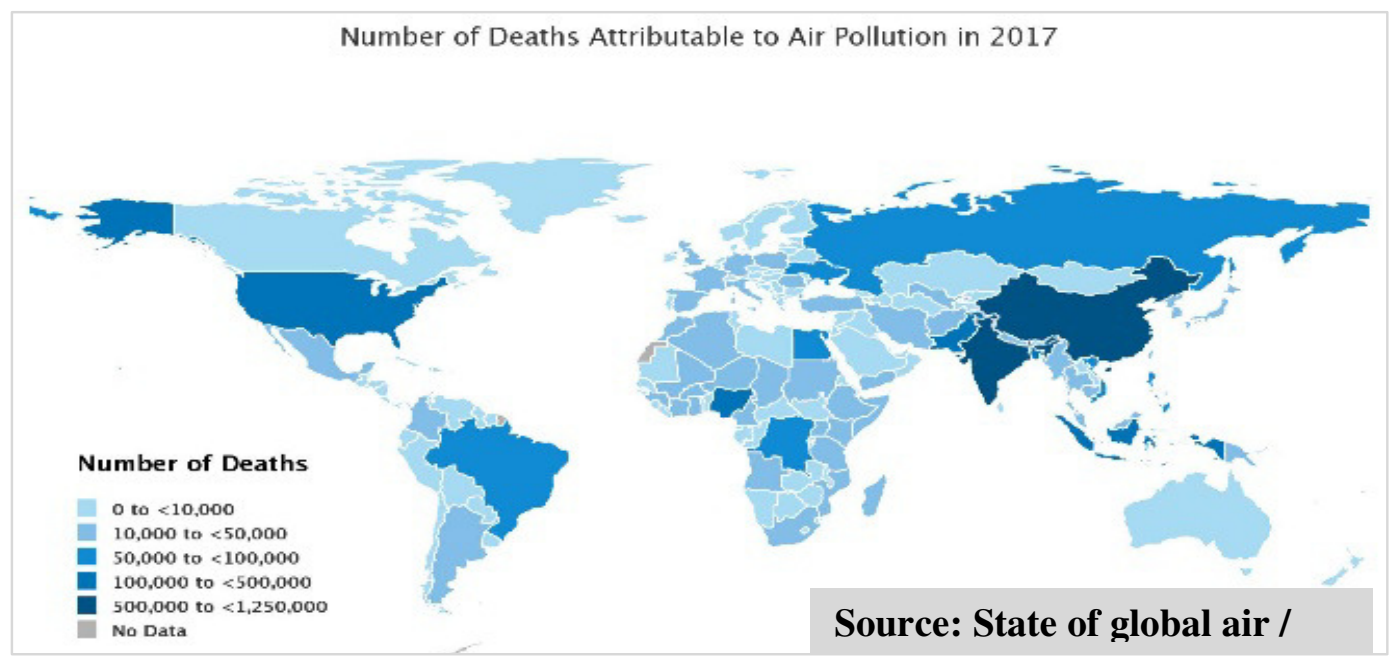

\section{E-vehicles-The Next game changer}

Though the e-vehicles were invented long ago, there were lot of difficulties and resistances in implementing the technology.

Now with the pollution levels hitting sky high, it is high time that we switch to alternate source of mobility reducing the usage of the conventional fossil fuel powered engines. With this context, the Government has already taken measures with its BS-6 implementation and various other initiatives to partially curb the usage of fossil fuels. The stage is now set to introduce the electric vehicles on a large scale in a phased manner ant is definitely going to be the game changer marching forward.

E-mobility will definitely get through the tail pipe targets. But the true success lies in overall Well to Wheel efficiency.

SWOT evaluation

Strength: The e-mobility sector is strongly backed up the push from the Indian Government. The vehicles emit carbon footprint and with minimal number of parts offer less maintenance cost and hassle free driving experience.

Weakness: Though the industry is attractive, there is a long way forward in practically implementing the technology to the road catering to the overall mobility requirement of the Indian market. Technologically, India needs to gear up in all respects to enable fruitful implementation.

Opportunities: Ample opportunities arise from the regulations front and population base. Step by step penetration of the technology from two-wheelers, three-wheelers, passenger cars and light to heavy duty vehicles is bound to happen in a phased manner.

Threats: Threats to the industry is the lack of clarity and infrastructure viabilities in India which may hamper or delay the timeline of implementation which creates a volatile state affecting the OEMs and end consumers to move towards a full electrification in the e-mobility sector. 


\section{Key challenges moving forward}

\section{Power source}

The heart of e-mobility is electricity stored in batteries and understanding the efficiency of the sources is instrumental in the successful implementation of electric vehicle projects.

A retrospective inspection into the sources suggest that a major portion (about $63.2 \%$ ) of the total power production comes from the thermal fossil fuel fired sources and only $22.7 \%$ of the power is generated from the renewable energy sources such as wind,solar,etc.

This data is the current scenario catering the domestic and industrial needs of the country.one has to now consider the enormous demand that will be placed over the shoulders of the power generation sector. Every car running on the road constantly needs power and forecasting the actual demand in numbers keeping the number of electrical vehicles under study will pose a massive target to the sources.

The indication is clear that e-mobility is realistic only upon building strong and sustainable power generation entities within the country. The Well to Wheel efficiency is crucial in deciding upon the overall effectiveness of the e-mobility implementation. The Government should focus on innovative ways to harness renewable efficiency. Otherwise the fuel which was used directly in the vehicles will be burned to generate electricity and indirectly propel electric vehicles.

\begin{tabular}{|c|c|c|}
\hline Fuel & MW & $\%$ of Total \\
\hline Total Thermal & $2,27,644$ & $63.2 \%$ \\
\hline Coal & $1,96,895$ & $54.2 \%$ \\
\hline Lignite & 6,260 & $1.7 \%$ \\
\hline Gas & 24,937 & $6.9 \%$ \\
\hline Diesel & 510 & $0.1 \%$ \\
\hline Hydro (Renewable) & 45,399 & $12.6 \%$ \\
\hline Nuclear & 6,780 & $1.9 \%$ \\
\hline RES* (MNRE) & 82,589 & $22.7 \%$ \\
\hline Total & 363,370 & \\
\hline
\end{tabular}

Table 1: Total Installed Capacity (As on 30.09.2019) - Source: Central Electricity Authority (CEA)

Infrastructure

The next important challenge is the transmission of power and distribution of power to the nook and corner of the country. 
When compared the losses in transporting fuel and transporting power, there is a significant difference in transmission efficiency. When we talk about $100 \%$ electrification, the concept is not simple task and requires the strengthening of infrastructure and charging facilities across the country. Depending on the traditional grid too is impractical as still 50 million homes still don't have access to electricity, information shared by Power Minister Mr.Piyush Goyal in the past.

\section{Consumer behavior}

The end effect of all the changes ultimately falls in the hands of the consumer and their behavior towards accepting this giant technology leap which will definitely hit their everyday life. A small analysis is made on the key factors that will affect the consumer behavior when they are pushed towards complete electrification.

Psychological: The consumers when confronted with change, typically exhibit a reluctant attitude towards it and with such a change which is pretty close to their life, challenge arises in motivating the consumers to accept the uncertainties that the e-mobility will bring. Consumers in this case don't really care about the benefits to the environment and look more into their own conveniences. As a result, the OEMs and the Government should clearly carve out pricing and implementation policies to give a positive push towards this transition.

Social: Socially, Indian consumers are largely influenced by the collective opinion and preferences of the masses and this will either benefit the transition or affect the same. The key concern with the electric vehicles like cost, recharging and safety is currently spell bound to various mixed opinions and posts a highly volatile state which has to be carefully molded.

\section{Auto Components}

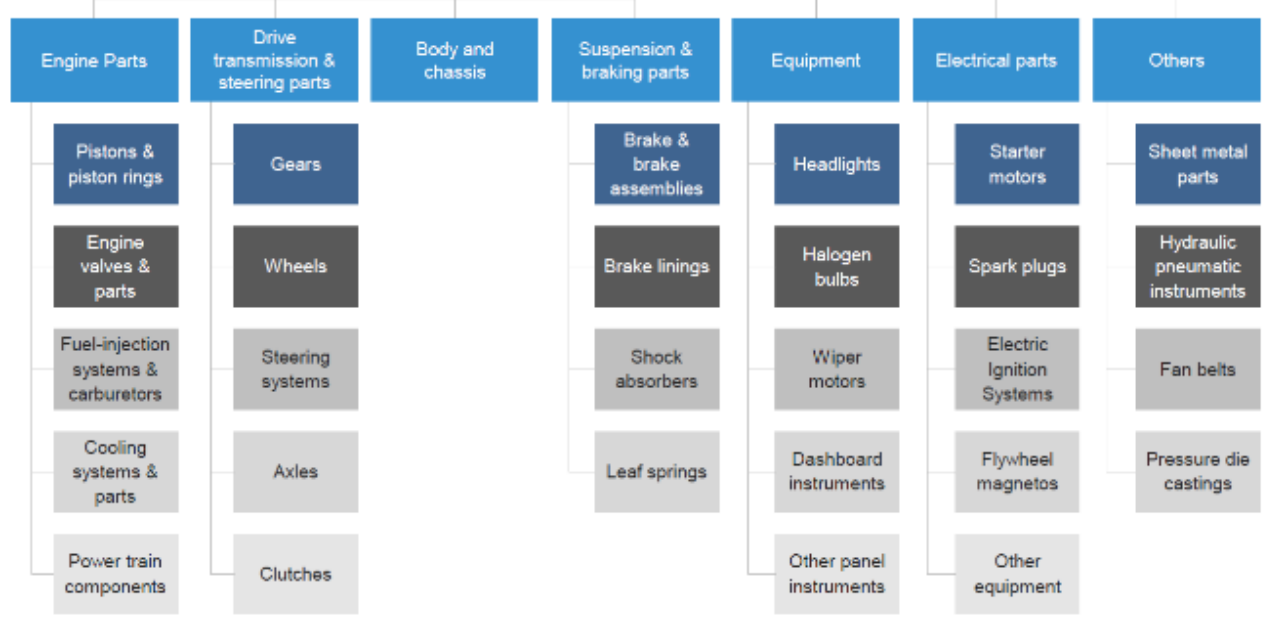

Source: ACMA

Cultural: Culturalinfluences, in this case has no major influence because the products are neutral and in the basket of everyday essential. Thusthe transition is robust to the cultural influences.

Personal: This is an important factor due to the fact that the conventional engine drive has created a plethora of experience with different age groups and replacing it with the flat torque drive characteristics will definitely post challenges to the automakers to restore the feel expected by the drivers with the motor. 
Economic: Needless to say, the price tags of the electric cars are definite show stoppers as it has a direct influence on the preference to other modes of public transport limiting the growth of the e-mobility. Unless customers are presented with the prices, well acceptable from all sectors, the dream of $100 \%$ electrification may face serious bottlenecks.

\section{IC and allied sector}

Referring the entire skeleton of the auto component framework, engine and engine related parts contribute a major share and the transition will affect its subsets.

\section{Domestic market potential by components (2020E)}

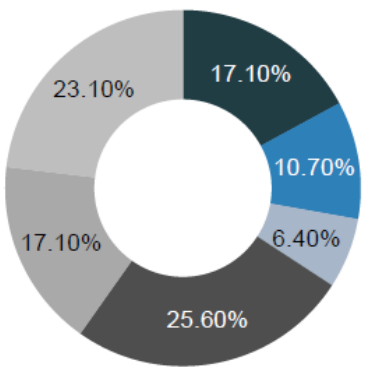

- Transmission and Steering

Parts

- Suspension and Braking

Parts

Interior

Engine \& Exhaust

Electronics and Electrical

Body \& Structure

\section{Export market potential by components (2020E)}

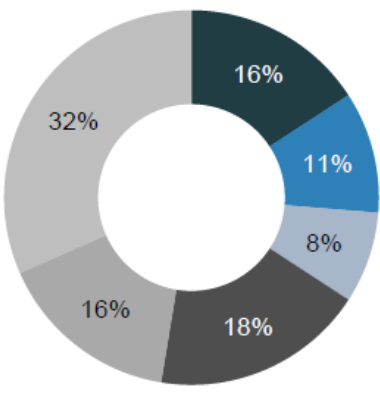

- Transmission and Steering Parts

- Suspension and Braking

Parts

Interior

Engine \& Exhaust

Electronics and Electrical

Body \& Structure

\section{Source:ACMA, News Sources}

The shares in figure of the domestic and export market clearly carves out the strong presence of the engine and supporting auxiliaries. The change is a disruption to the larger quantum of operations and the OEMs and SMEs must definitely take measures to assess the 
risk and mitigate it with alternatives. Swift and agile transformation is the need of the hour to sustain the stand in the automotive business going forward.

There are mechanics who make their living by fixing ICE run vehicles and have all the knowledge they need, and can go to any extent to work on a seized car, since they have erudite from their practice, but once the traction motorized based EVs are launched the mechanic shops would be the first to blackout because they can't comprehend the electronics and sophisticated mechatronics technology in operating the EVs.

\section{Paradigm shift in employment}

Employment uncertainty is another debatable factor. At present, approximately 2,000 parts of a car is being produced and congregated. Automation and orientation towards robotics is very much in the nascent stage and demands skills. Once EVs, which has approximately 20 parts, come into play, there will be major job losses and a further decrease of the already decreasing employment rate. There would be plenty of layoffs and it will certainly not be good for the holistic growth of India.

PMKVY (Pradhan Mantri Kaushal Vikas Yojana) is been launched by the central government for meeting the skill development of unemployed youth, demanded by the EV market. This being alternative motive of PMKVY and a positive vision to make sure that the skills are available before a red signal for specific requirements.

\section{Peek into the Globe}

A white paper is been submitted by the SIAM (Society of Indian Automobile Manufacturers) with number of recommendations to encourage people to adopt to EV's. The recommendations are

1. Reduction in GST from $12 \%$ to $5 \%$.

2. Waving or rebating the road taxes and toll

3. Tax benefits (Income tax benefits)

4. Free parking

5. Fifty percentage reduction in the power tariff.and

6. free battery charging points.

Norway was the first country to practice similar things and was able to acquire 32 percent EV market in 2016. Norway is continuing such strategies to achieve 50 percent EV market by 2025. India sure can adopt such strategies to increase the potent of EV's. India can bring incentives for clean electric vehicles but can charge premium for fossil fuel vehicles.

Through targeting public vehicles such as buses, taxis and 3 wheelers, the inclusion of EV in the dense ICE market can be introduced. Since maximumnumber of vehicles are owned by state, promoting electric vehicle in this segment becomes easy. China has adopted similar plan to enhancesales of electric cars on the market, and currently stands at $2 \%$ of 24.7 million annual sales of electric cars.

\section{Conclusion}

It is evident from the above facts and figures that India will positively achieve e-mobility. The atmosphere of the ultimatum is difficult but not impossible to reach. If India really wants to accomplish the mission, it will be a concerted effort on the part of citizens of this country. 
The offers in the form of tax incentives may encourage the customers to move out of the traditional mind set and prefer EV's.

India is experiencing an alarming high level of pollution hence EV's will become essential than luxury. Strict guidelines and a time-managed framework should be laid down as to how changes will occur and how to make the most of them. In each field there are strengths and weaknesses that need to be understood and eradicated.

Future vehicle technology in India should have hybrid option for fuel, particularly for high end models.In any field, $100 \%$ dependency on a particular technology is unrealistic and concerned stakeholders must bring out a golden balance for well-being of all in every respect to make this transition successful.

\section{References}

[1] Health Effects Institute. 2019. State of Global Air 2019. Special Report. Boston, MA: Health Effects Institute.ISSN 2578-6873.

[2] Pandit, S., \&Kapur, D. (2015). Electric Vehicles in India Policies, Opportunities and Current Scenario. In ADB Open Innovation Forum.

[3] Shepherd, S., Bonsall, P., \& Harrison, G. (2012). Factors affecting future demand for electric vehicles: A model based study. Transport Policy, 20, 62-74.

[4] https://niti.gov.in/writereaddata/files/document_publication/EV_report.pdf

[5] https://www.mckinsey.com/industries/automotive-and-assembly/our-insights/the-future-ofmobility-in-india-challenges-and-opportunities-for-the-auto-component-industry

[6] http://niti.gov.in/writereaddata/files/document_publication/RMI_India_Report_web.pdf

[7] http://niti.gov.in/writereaddata/files/document_publication/India-Energy-Storage-Mission.pdf 